\title{
Studies on the permeability of the blood-brain barrier in experimental diabetes
}

\author{
M. Lorenzi ${ }^{1}$, D.P. Healy ${ }^{2}$, R. Hawkins ${ }^{2}$, J. M.Printz ${ }^{2}$ and M.P.Printz ${ }^{2}$ \\ ${ }^{1}$ Department of Medicine, Division of Endocrinology and Metabolism \\ and ${ }^{2}$ Division of Pharmacology, University of California San Diego, La Jolla, California, USA
}

\begin{abstract}
Summary. Whether the increased capillary permeability characteristic of diabetes extends to the blood-brain barrier is presently unclear. We have examined in streptozotocin-diabetic rats the permeability of the blood-brain barrier at the level of 12 discrete brain regions employing 3 intravenous tracers of different molecular weight: sucrose, inulin and horseradish peroxidase. In animals killed $5 \mathrm{~min}$ after tracer injection both the sucrose and the inulin spaces were similar to controls. In order to assess whether more prolonged circulation of tracers would uncover leakage, we studied brain spaces at longer intervals after tracer injections. When inulin was allowed to circulate for 15 min prior to killing, animals with 4 weeks of diabetes (but not 2 weeks) exhibited larger inulin spaces at the
\end{abstract}

level of the medio-basal hypothalamus $(p<0.01)$, medio-dorsal hypothalamus $(p<0.05)$ and periaqueductal gray $(p<$ 0.01 ). Horseradish peroxidase, even after $75 \mathrm{~min}$ of perfusion, remained confined in both diabetic and control animals to central nervous system areas devoid of blood-brain barrier. Thus, after a relatively short duration of diabetes the bloodbrain barrier manifests an increased permeability. It is subtle, limited to some brain regions and selective for low molecular weight tracers.

Key words: Diabetes, vascular permeability, blood-brain barrier, sucrose, inulin, horseradish peroxidase, albumin.
The most characteristic vascular lesion of long-term diabetes mellitus is widespread increased permeability of microvessels [1-3]. At the level of retinal capillaries, the most-studied among vessels with tight barrier properties, a relationship is evident between duration of the diabetic state and degree of barrier incontinence as assessed by the size of the permeant molecules. Thus, in humans the blood-retinal barrier becomes permeable to small molecules such as fluorescein (mol. wt.367) at very early stages of diabetes and in the absence of morphologic features of retinopathy $[4,5]$; after a few years of disease, leakage of plasma proteins from retinal capillaries results in the hard exudates of established background retinopathy [2]. Progressive incontinence is confirmed by studies in animals with experimentally-induced diabetes $[6,7]$.

Indirect observations in humans [8] suggest the possibility that the competence of the blood-brain barrier may also be affected by diabetes. Experimental studies have, however, been limited and have yielded contradictory findings. While a study has failed to detect leakage of either horseradish peroxidase (mol. wt. 40000) or cytochrome c (mol. wt. 12000) at the level of the cerebral cortex after 4-20 weeks of streptozotocin diabetes
[9], other investigators using the same experimental model have reported cortical extravasation of endogenous albumin (mol. wt. 69000) as early as two weeks after induction of diabetes [10].

Since it would be clinically relevant to identify whether and to what extent the barrier between blood and brain is indeed compromised even after short duration of diabetes, we have attempted to increase the sensitivity of detection by employing substances of smaller molecular weight and investigating the time course and dynamics of leakage into discrete brain regions of rats with varying duration of streptozotocin diabetes.

\section{Materials and methods}

Six groups of 10-15 adult Sprague Dawley male rats (Charles River Breeding, Kingston, New Jersey, USA) weighing 200-250g were made diabetic by injection of streptozotocin $(6.5 \mathrm{mg} / 100 \mathrm{~g}$ body weight) through the tail vein under light ether anaesthesia. Development of diabetes was verified at $48 \mathrm{~h}$ after injection by semi-quantitative testing for glycosuria and ketonuria (Ketodiastix, Ames Division, Miles Laboratories, Elkhart, Indiana, USA) and measurement of plasma glucose was verified by a glucose oxidase method (Beckman Instruments, Fullerton, California, USA). A second plasma glucose measurement was obtained in control and experimental animals 1-2 
Table 1. Brain sucrose and inulin spaces $5 \mathrm{~min}$ after intrajugular injection in rats with 4 weeks of experimental diabetes

\begin{tabular}{|c|c|c|c|c|c|c|}
\hline \multirow[t]{2}{*}{ Brain region } & \multicolumn{2}{|c|}{ Weight $^{a}(\mathrm{mg})$} & \multicolumn{2}{|c|}{$\begin{array}{l}\text { Sucrose space }{ }^{\mathrm{a}} \\
(\% \mu \mathrm{l} \text { plasma } / \mathrm{mg} \text { region weight })\end{array}$} & \multicolumn{2}{|c|}{$\begin{array}{l}\text { Inulin space }{ }^{\mathrm{a}} \\
(\% \mu \mathrm{l} \text { plasma/mg region weight })\end{array}$} \\
\hline & $\begin{array}{l}\text { Diabetic } \\
(n=15)\end{array}$ & $\begin{array}{l}\text { Control } \\
(n=10)\end{array}$ & $\begin{array}{l}\text { Diabetic } \\
(n=6)\end{array}$ & $\begin{array}{l}\text { Control } \\
(n=5)\end{array}$ & $\begin{array}{l}\text { Diabetic } \\
(n=9)\end{array}$ & $\begin{array}{l}\text { Control } \\
(n=5)\end{array}$ \\
\hline Olfactory bulb & $58 \pm 4$ & $77 \pm 7$ & $4.1 \pm 0.7$ & $4.1 \pm 0.3$ & $4.5 \pm 1.7$ & $4.8 \pm 1.5$ \\
\hline Pre-optic area & $14 \pm 3$ & $15 \pm 3$ & $2.9 \pm 0.5$ & $3.2 \pm 0.8$ & $2.6 \pm 0.2$ & $2.7 \pm 0.3$ \\
\hline Septum & $13 \pm 4$ & $14 \pm 1$ & $2.3 \pm 0.3$ & $2.2 \pm 0.3$ & $1.5 \pm 0.3$ & $1.5 \pm 0.2$ \\
\hline Anterior hypothalamus & $10 \pm 3$ & $12 \pm 3$ & $2.1 \pm 0.4$ & $2.3 \pm 0.2$ & $2.4 \pm 0.6$ & $3.1 \pm 0.9$ \\
\hline Medio-basal hypothalamus & $4 \pm 1$ & $5 \pm 1$ & $3.6 \pm 0.6$ & $3.6 \pm 0.7$ & $4.5 \pm 1.3$ & $3.9 \pm 1.0$ \\
\hline Medio-dorsal hypothalamus & $4 \pm 2$ & $5 \pm 2$ & $2.1 \pm 0.7$ & $2.2 \pm 0.2$ & $1.9 \pm 0.9$ & $1.7 \pm 0.5$ \\
\hline Thalamus & $9 \pm 2$ & $11 \pm 3$ & $2.2 \pm 0.4$ & $2.4 \pm 0.3$ & $1.6 \pm 0.4$ & $1.7 \pm 0.5$ \\
\hline Medial cingulate cortex & $33 \pm 8$ & $38 \pm 10$ & $3.7 \pm 0.5$ & $4.1 \pm 0.4$ & $2.7 \pm 0.5$ & $3.0 \pm 0.7$ \\
\hline Frontal cortex & $32 \pm 11$ & $41 \pm 12$ & $3.5 \pm 0.4$ & $3.9 \pm 0.4$ & $3.0 \pm 0.7$ & $2.9 \pm 0.7$ \\
\hline Periaqueductal gray & $4 \pm 1$ & $5 \pm 2$ & $2.1 \pm 0.5$ & $2.0 \pm 0.1$ & $2.4 \pm 0.8$ & $2.1 \pm 0.6$ \\
\hline Ventrotegmental area & $7 \pm 3$ & $9 \pm 3$ & $2.4 \pm 0.4$ & $3.0 \pm 0.3$ & $2.0 \pm 0.4$ & $1.9 \pm 0.3$ \\
\hline
\end{tabular}

a All data are presented as mean $\pm 1 \mathrm{SD}$

Table 2. Brain inulin space 15 min after intrajugular injection in rats with 2 or 4 weeks of experimental diabetes

\begin{tabular}{|c|c|c|c|c|}
\hline \multirow[t]{2}{*}{ Brain Region $^{\mathrm{a}}$} & \multicolumn{2}{|c|}{$\begin{array}{l}\text { Inulin space } \overline{\mathrm{p}} 2 \text { weeks of } \mathrm{DM}^{\mathrm{a}} \\
(\% \mu \mathrm{l} \text { plasma/mg region weight })\end{array}$} & \multicolumn{2}{|c|}{$\begin{array}{l}\text { Inulin space } \overline{\mathrm{p}} 4 \text { weeks of } \mathrm{DM}^{\mathrm{a}} \\
\text { (\% } \% \text { l plasma } / \mathrm{mg} \text { region weight })\end{array}$} \\
\hline & Diabetic $(n=6)$ & Control $(n=6)$ & $\begin{array}{l}\text { Diabetic } \\
(n=7)\end{array}$ & $\begin{array}{l}\text { Control } \\
(n=7)\end{array}$ \\
\hline Olfactory bulb & $2.6 \pm 1.4$ & $2.1 \pm 0.3$ & $2.0 \pm 0.3$ & $2.2 \pm 0.4$ \\
\hline Preoptic area & $1.9 \pm 0.6$ & $1.8 \pm 0.4$ & $2.7 \pm 1.0$ & $2.4 \pm 0.6$ \\
\hline Septum & $1.0 \pm 0.1$ & $1.1 \pm 0.3$ & $1.0 \pm 0.3$ & $1.1 \pm 0.2$ \\
\hline Ventro-anterior hypothalamus & $1.4 \pm 0.7$ & $1.8 \pm 0.2$ & $3.6 \pm 1.3$ & $3.3 \pm 0.6$ \\
\hline Dorso-anterior hypothalamus & $1.3 \pm 0.8$ & $1.2 \pm 0.6$ & $2.6 \pm 1.4$ & $2.2 \pm 1.0$ \\
\hline Medio-basal hypothalamus & $3.4 \pm 0.7$ & $3.1 \pm 0.8$ & $5.4 \pm 1.2 p<0.01$ & $3.9 \pm 0.8$ \\
\hline Medio-dorsal hypothalamus & $1.4 \pm 0.2$ & $1.2 \pm 0.5$ & $2.7 \pm 0.5 p<0.05$ & $1.8 \pm 0.5$ \\
\hline Thalamus & $0.8 \pm 0.2$ & $0.8 \pm 0.3$ & $1.0 \pm 0.1$ & $1.1 \pm 0.2$ \\
\hline Medial cingulate cortex & $1.6 \pm 1.2$ & $1.8 \pm 0.4$ & $1.8 \pm 0.2$ & $2.0 \pm 1.0$ \\
\hline Frontal cortex & $1.6 \pm 0.8$ & $1.3 \pm 0.2$ & $1.2 \pm 0.2$ & $1.0 \pm 0.2$ \\
\hline Periaqueductal gray & $1.6 \pm 0.3$ & $1.2 \pm 0.2$ & $5.6 \pm 2.0 p<0.01$ & $1.8 \pm 0.5$ \\
\hline Ventrotegmental area & $1.2 \pm 0.6$ & $1.3 \pm 0.4$ & $1.6 \pm 0.4$ & $1.4 \pm 0.5$ \\
\hline
\end{tabular}

a All data are presented as mean $\pm 1 \mathrm{SD}$

days prior to the experiments. Weights were recorded every 3-4 days. Blood-brain barrier permeability was studied employing as tracers sucrose, mol. wt. $342\left[{ }^{14} \mathrm{C}(\mathrm{U})\right.$ sucrose, $1 \mathrm{mCi} / 330 \mu \mathrm{l}$; Amersham, Arlington Heights, Illinois, USA], inulin, a non-metabolizable polymer of fructose with an average mol. wt. of $5000\left[{ }^{3} \mathrm{H}(\mathrm{G})\right.$ inulin, $98 \%$ pure; New England Nuclear, Boston, Massachussets, USA], and horseradish peroxidase (HRP), mol. wt. approximately 40000 (HRP Type II; Sigma Chemicals, St. Louis, Missouri, USA). Inulin and HRP have previously been shown to be normally confined to the intravascular space of the brain [11-13]; sucrose has a slightly larger brain space which steadily increases over time, possibly as a consequence of intracellular distribution [12]. In order to study rapid passage of tracers, animals were killed $5 \mathrm{~min}$ after injection of sucrose or inulin. Duration of diabetes was 4 or 8 weeks. In order to enhance the chance of leakage with multiple passages, animals in other experiments were killed $15 \mathrm{~min}$ after the injection of inulin or $75 \mathrm{~min}$ after the injection of HRP. Duration of diabetes in these experiments was 2 or 4 weeks.

On the morning of the experiments, a cannula of silastic tubing was inserted into the left jugular vein of each animal under light ether anaesthesia, following the method of Harms and Ojeda [14]. The animals were then housed individually and allowed free access to water. Four to $6 \mathrm{~h}$ later the injections of test materials were administered. Sucrose or inulin were dissolved in $\mathrm{NaCl} 154 \mathrm{mmol} / 1$, and $40 \mu \mathrm{Ci}$ was injected in $100 \mu \mathrm{l}$ volume through the jugular cannula, followed by $100 \mu \mathrm{l}$ of $\mathrm{NaCl}$. The animals were lightly restrained in a towel during the injection and returned to their cages immediately thereafter. After exactly 5 or $15 \mathrm{~min}$, depending on the experiment, the animals were decapitated and trunk blood was collected in centrifuge tubes containing $100 \mu \mathrm{l}$ EDTA $100 \mathrm{mmol} / \mathrm{p} \mathrm{pH} 7.4$ maintained on ice. The skull was immediately opened, and the entire brain was carefully removed and placed on aluminum foil on dry ice. The plasma was separated by centrifugation, and three $25 \mu \mathrm{l}$ aliquots from each sample were collected in pre-weighed scintillation vials. Brains and plasma samples were stored at $-70^{\circ} \mathrm{C}$ for $3-4$ days until processing. Brains were sliced and dissected free hand into the regions listed in Tables 1 and 2. Each region was deposited in a pre-weighed scintillation vial with plastic-lined cap and weighed on a Mettler H51 balance. For radioactivity counting each tissue sample or $25 \mathrm{ul}$ aliquot of plasma was digested with $500 \mu$ l of NCS tissue solubilizer (Amersham). Vials were shaken in an Eberbach shaker (Eberbach, Ann Arbor, Michigan, USA) for 2 to 3 days at room temperature, and completeness of digestion was verified by evaluating that no particulate aliquots of the tissue sample remained visible. On a few occasions it was necessary to incubate the vials in a water bath at $50^{\circ} \mathrm{C}$ for $2 \mathrm{~h}$ to insure complete digestion. The digest was neutralized by adding $17 \mu \mathrm{l}$ of glacial acetic acid to each vial. Twenty milliliters of OCS scintillation fluid (Amersham) were then added, the vials were shaken for 2 to $3 \mathrm{~h}$ and then dark-adapted at room temperature for $24 \mathrm{~h}$ prior to radioactivity determination with a Searle Delta 300 scintillation counter (Des Plaines, Illinois, USA) programmed for automatic quench correction. Counting efficiency was $30 \%$ for ${ }^{3} \mathrm{H}$ and $70 \%$ for ${ }^{14} \mathrm{C}$.

The $5 \mathrm{~min}$ sucrose or inulin space of each brain region was com- 
puted as follows: $\mathrm{cpm} /$ region divided by region weight (in $\mathrm{mg}$ ) to yield $\mathrm{cpm} / \mathrm{mg}$ tissue; the latter value divided by $\mathrm{cpm} / \mu \mathrm{l}$ of plasma and then multiplied by 100 to yield the respective spaces as percent $\mu l$ plasma/mg area. The $15 \mathrm{~min}$ inulin space was calculated in the same manner, except that the $\mathrm{cpm} / \mu \mathrm{l}$ of plasma were the average of $5 \mathrm{~min}$ and $15 \mathrm{~min}$ plasma radioactivity values in order to approach an integrated input function.

For the HRP studies, experimental and control animals were cannulated as described above. Ten min prior to the injection of HRP, rats were administered $2 \mathrm{mg} / \mathrm{kg}$ of diphenhydramine $\mathrm{HCl}$ (Benadryl; Parke-Davis, Morris Plains, New Jersey, USA) intramuscularly in order to prevent anaphylaxis. A total of $50 \mathrm{mg} / \mathrm{kg}$ HRP dissolved in $\mathrm{NaCl} 154 \mathrm{mmol} / 1$ was then infused over a 3 to $4 \mathrm{~min}$ period through the jugular cannula. Sixty-five min later rats were injected with heparin $100 \mathrm{U}$ intraperitoneally, followed at $70 \mathrm{~min}$ by $50 \mathrm{mg} / \mathrm{kg}$ pentobarbitol sodium (Nembutal; Abbot Pharmaceuticals, North Chicago, Illinois, USA) by the same route. At $75 \mathrm{~min}$ the animals were killed by cardiac perfusion with $0.1 \mathrm{~mol} / 1$ phosphate buffer $(\mathrm{pH} 7.4)$ followed by a solution consisting of $1 \%$ paraformaldehyde and $1.25 \%$ glutaraldehyde in phosphate buffer. After $20 \mathrm{~min}$ of perfusion the brain was dissected from the skull. Frontal sections $40 \mu$ thick were obtained in a cryostat at $-20^{\circ} \mathrm{C}$ and processed for HRP according to the tetramethylbenzidine method of Mesulam [15]. The reaction product was evaluated with light microscopy under bright and dark field.

\section{Statistical analysis}

Results are expressed as mean \pm SD. Statistical analysis of plasma concentrations (glucose, radioactivity) was performed using the twotailed Student's t-test (unpaired analysis). Comparison of brain spaces in normal and diabetic animals was performed by two factor analysis of variance, followed by the Fisher's least significant difference test and by the Duncan's multiple range testing for comparison of individual regions.

\section{Results}

\section{Metabolic data}

By $48 \mathrm{~h}$ after the injection of streptozotocin, animals had developed hyperglycaemia and glycosuria; in a few, ketonuria was also present but cleared within a few days. After 2 weeks of diabetes, weight gain had been $74 \pm 6 \mathrm{~g}$ as compared to $114 \pm 16 \mathrm{~g}$ in the controls. After four weeks of diabetes, weight gain was $32 \pm 15 \mathrm{~g}$ versus $128 \pm 24$ in controls, and after 8 weeks $47 \pm 16$ versus $154 \pm 22$ in controls. Random plasma glucose obtained in the afternoon was $28.8 \pm 2.7 \mathrm{mmol} / 1$ in the diabetic animals and $8 \pm 0.5 \mathrm{mmol} / 1$ in the controls $(p<0.001)$.

\section{Brain sucrose and inulin space}

In initial experiments the sucrose and inulin space of discrete brain regions was evaluated $5 \mathrm{~min}$ after the injection of the tracer in animals with either 4 or 8 weeks of diabetes and in respective controls. The data obtained after 8 weeks of diabetes were essentially identical to those obtained after 4 weeks (Table 1). The sucrose space tended to be slightly larger than the inulin space, in accordance with previous observations [12]. For both tracers, and for inulin in particular, the largest values were observed in the olfactory bulb and in the medio-basal hypothalamus. No differences were observed between control and diabetic animals.
We next explored whether repeated passages of the tracer substance would uncover subtle degrees of leakage in the diabetic animals. Inulin was allowed to circulate for $15 \mathrm{~min}$ before killing; by this time, since animals were not nephrectomized, a sizable amount of the radioactive inulin had been excreted through the kidneys and distributed to muscle and other freely permeable tissues $[12,16]$. Thus, in control animals the circulating radioactivity at $15 \mathrm{~min}$ was only $280 \pm 51 \mathrm{cpm} / \mu 1$ versus $648 \pm 156$ at $5 \mathrm{~min}$; in the diabetic animals it was $195 \pm 63 \mathrm{cpm} / \mu \mathrm{l}$ versus $735 \pm 200$ at $5 \mathrm{~min}$. Although the difference for the 15 min plasma radioactivity was highly significant between control and diabetic animals $(p<0.005)$, the average of the 5 - and 15 -min values employed in the calculation of brain inulin space was identical in control $(462 \pm 46 \mathrm{cpm} / \mu \mathrm{l})$ and diabetic animals $(465 \pm 36 \mathrm{cpm} / \mu \mathrm{l})$. The data for the 15 -min brain inulin space are presented in Table 2 . While 2 weeks of diabetes did not appear to significantly alter the inulin distribution space, animals with 4 weeks of diabetes had a mean inulin space for the 12 regions examined that was significantly greater than in control animals ( $\mathrm{F}$ ratio $=8.96, p=0.003)$. The diabetic state had significantly different effects upon different regions ( $\mathrm{F}$ ratio for interactions $=5.55, p<0.0001$ ). Three discrete brain regions manifested increased permeability in the diabetic animals: the medio-basal hypothalamus $(p<0.01)$, the medio-dorsal hypothalamus $(p<0.05)$ and the periaqueductal gray $(p<0.01)$.

\section{Horseradish peroxidase distribution}

To examine the integrity of the blood-brain barrier to larger size molecules in animals with 4 weeks of diabetes, HRP was injected intravenously and allowed to circulate for $75 \mathrm{~min}$. As expected, in both control and diabetic animals areas of the brain lacking a barrier were heavily stained. These areas included the circumventricular organs - subfornical organ, organum vasculosum laminae terminalis, median eminence, area postrema as well as the pineal gland and choroid plexus. The brain parenchyma was uniformly unstained in diabetic and control animals. In a single diabetic animal we observed occasional focal areas of leakage of HRP; the significance of this leakage remains unclear since it occurred in only one animal.

\section{Discussion}

The vascular pathology of diabetes is characterized by widespread increased capillary permeability [1-5], and clinical observations indirectly suggest that the bloodbrain barrier might share in this abnormality [8]. Since the available experimental evidence is contradictory $[9$, 10 ], we have examined the question by focusing on discrete brain regions and by employing tracers of largely different molecular weight (sucrose, inulin and HRP). 
The results clearly indicate that up to 8 weeks of non-ketotic diabetes failed to induce gross disruption of the blood-brain barrier. Our observations should in fact be contrasted with those obtained upon osmotic [17, 18], toxic [19], or hypertensive [20] opening of the barrier, situations in which leakage of tracers is immediate and extends to large molecular weight substances.

On the other hand, the small increase in inulin space of selected regions in diabetic animals suggests that, even at early stages of diabetes, an impairment of barrier systems may occur in the brain as it occurs in the retina $[4,5]$. The methodology we have used to obtain and calculate the inulin space of discrete brain regions has been employed by other investigators [11, 12, 16], albeit generally for larger brain samples and in nephrectomized animals. The brain inulin space reported in such studies varied between 1 and $3.3 \%$ of the tissue wet weight, figures in very good agreement with our findings in normal animals. Inulin space of a given anatomical brain region reflects not only the vascular plasma space of the same region, but also reflects leakage from the vascular compartment, as documented by two sets of observations. First, the medio-basal hypothalamus, which is the poorest among hypothalamic and other brain regions in capillary density [21], consistently manifested in this and previous studies [22] the largest inulin space in accordance with the knowledge that its bloodbrain barrier is only partial $[21,23]$. Second, the brain inulin space is responsive to physiologic or pharmacologic changes in blood-brain barrier permeability, as it decreases with maturation of barrier competence [16] and it increases with iatrogenic barrier disruption [17]. A significant increase in brain inulin space in the diabetic animals was selectively observed when inulin was allowed to circulate for $15 \mathrm{~min}$ (but not for $5 \mathrm{~min}$ ), militating against a possible confounding role of differences in the weight of the brain regions in the diabetic animals.

The confinement of a statistically significant increase in inulin space to the medial regions of the hypothalamus and to the periaqueductal gray has several possible interpretations which are not mutually exclusive. It may to some extent represent an underestimation of a more widespread increase in vascular permeability. In fact, since the animals were not nephrectomized, circulating inulin radioactivity declined rather rapidly, and declined significantly more so in the diabetic animals. Thus, in diabetic animals the brain might have been exposed for some time to a lesser amount of the tracer. On the other hand, the increased inulin space of the medial hypothalamus and the periaqueductal gray may indeed indicate preferential areas of leakage. This could be consequent to their vicinity to the ventricular system and thus to CSF. The alteration induced by diabetes would then have occurred - rather than at the level of the capillary endothelium - at the level of the choroidal epithelium [24]. In this case, however, another paraventricular region, the septum, should also have displayed an increased inulin space. An alternate inter- pretation could be proposed. The hypothalamic periventricular regions (and posterior hypothalamic area) host the descending pathway for the drinking response which ends in the mesencephalic periaqueductal gray [25]. Because of their degree of hyperglycaemia, diabetic animals are severely polyuric and they responded to intracellular dehydration and some degree of hypovolaemia with polydipsia. An enhanced activity of the drinking pathway in these animals would be accompanied by an increased blood flow to the structures involved, which would uncover a slowly developing defect in blood-brain barrier competence. A direct relationship between increase in blood flow and increase in barrier permeability has been demonstrated in other experimental situations [20].

The results of the present experiments need to be corroborated by additional investigations. In particular, studies in nephrectomized animals will minimize [12, 26] the interpretative problems caused by rapid plasma disappearance of the tracers. The role of regionally altered vascularity will be addressed by measuring ${ }^{51} \mathrm{Cr}$ labeled erythrocytes pool in individual regions; anatomical localization of leakage will be more precisely defined by autoradiography and sampling of CSF.

The increased permeability of the blood-brain (or CSF) barrier detected in experimental animals may have a bearing on clinical observations, possibly contributing to the complex neurologic dysfunction associated with non-ketotic hyperglycaemia [27] and to the disturbed regulation of growth hormone secretion characteristic of poorly-controlled diabetes [8, 28, 29]. Neither our findings nor those of a previous study [9] offer, however, a suitable explanation for the observed extravasation of endogenous albumin in the cerebral cortex of short-term diabetic rats [10]. It is tempting to speculate that such abnormality might be consequent not to blood-brain barrier disruption, but rather to altered interactive properties of the endogenous albumin molecule with the vascular endothelium. Akin to other proteins, albumin undergoes extensive glycosylation in diabetes [30] and, at least in vitro, glycosylated albumin is avidly and preferentially pinocytosed by microvessels [31]. Transvascular passage of albumin could thus represent an abnormality of diabetic vessels which is not mediated by gross disruption of barrier systems but which may nonetheless contribute to disturbed parenchymal fluid homeostasis.

Acknowledgements. We are indebted to Professor A. Lein for assistance with statistical analysis of the data. This work was supported by grants from the American Diabetes Association, Southern California Affiliate, The Charles E. Culpeper Foundation to Dr. Lorenzi and by grant HL 25457 SCOR Hypertension to Dr. M. P. Printz.

\section{References}

1. Parving $\mathbf{H}-\mathbf{H}$ (1976) Increased microvascular permeability to plasma proteins in short- and long-term juvenile diabetics. Diabetes 25 (Suppl 2): 884-889 
2. Palmberg PF (1977) Diabetic retinopathy. Diabetes 26: 703-711

3. Mogensen CE, Christensen CK, Vittinghus E (1983) The stages in diabetic renal disease with emphasis on the stage of incipient diabetic nephropathy. Diabetes 32 (Supp1 2): 64-78

4. Cunha-Vaz JG, Gray JR, Zeimer RC, Mota MC, Ishimoto BM, Leite $E$ (1985) Characterization of the early stages of diabetic retinopathy by vitreous fluorophotometry. Diabetes 34: 53-59

5. Dorchy H, Toussaint C, Devroede M, Ernould C, Loeb H (1977) Diagnostic de la retinopathie diabetique infantile par angiographie fluoresceinique. Nouv Presse Med 6: 345-347

6. Tso MOM, Cunha-Vaz JG, Shih C-Y, Jones CW (1980) Clinicopathologic study of blood-retinal barrier in experimental diabetes mellitus. Arch Ophthalmol 98: 2032-2040

7. Wallow IHL, Engerman RL (1977) Permeability and patency of retinal blood vessels in experimental diabetes. Invest Ophthalmol Vis Sci 16: 447-461

8. Lorenzi M, Karam JH, McIlroy MB, Forsham PH (1980) Increased growth hormone response to dopamine infusion in insulin-dependent diabetic subjects: indication of possible bloodbrain barrier abnormality. J Clin Invest 65: 146-153

9. Jakobsen J, Malmgren L, Olsson Y (1978) Permeability of the blood-nerve barrier in the streptozotocin-diabetic rat. Exp Neurol 60: $277-285$

10. Stauber WT, Ong S-H, McCuskey RS (1981) Selective extravascular escape of albumin into the cerebral cortex of the diabetic rat. Diabetes 30: 500-503

11. Morrison $A B$ (1959) The distribution of intravenously-injected inulin in the fluids of the nervous system of the dog and rat. J Clin Invest 38: 1769-1777

12. Reed DJ, Woodbury DM (1963) Kinetics of movement of iodide, sucrose, inulin and radio-iodinated serum albumin in the central nervous system and cerebro-spinal fluid of the rat. J Physiol 169: $816-850$

13. Reese TS, Karnovsky MJ (1967) Fine structural localization of a blood-brain barrier to exogenous peroxidase. J Cell Biol 34: 207-217

14. Harms PG, Ojeda SR (1974) A rapid and simple procedure for chronic cannulation of the rat jugular vein. J Appl Physiol 36: 391-392

15. Mesulam M-M (1978) Tetramethyl benzidine for horseradish peroxidase neurohistochemistry: a non-carcinogenic blue reaction product with superior sensitivity for visualizing neural afferents and efferents. J Histochem Cytochem 26: 106-117

16. Ferguson RK, Woodbury DM (1969) Penetration of ${ }^{14} \mathrm{C}$-inulin and ${ }^{14} \mathrm{C}$-sucrose into brain, cerebrospinal fluid, and skeletal muscle of developing rats. Exp Brain Res 7: 181-194

17. Thompson AM (1970) Hyperosmotic effects on brain uptake of non-electrolytes. In: Crone C, Lassen NA (eds) Capillary Permeability. Pedersens V Bogtrykkeri A/S, Copenhagen, p 459-467

18. Barranger JA, Rapaport SI, Fredericks WR, Pentchev PG, MacDermot KD, Steusing JK, Brady RO (1979) Modification of the blood-brain barrier: increased concentration and fate of enzymes entering the brain. Proc Natl Acad Sci USA 76: 481-485

19. Cooper PH, Novin D, Butcher LL (1982) Intracerebral 6-hydroxydopamine produces extensive damage to the blood-brain barrier in rats. Neurosci Lett 30: 13-18

20. Heistad DD, Marcus ML (1979) Effect of sympathetic stimulation on permeability of the blood-brain barrier to albumin during acute hypertension in cats. Circ Res $45: 331-338$

21. De La Torre JC (1971) The blood-brain barrier for L-Dopa in the hypothalamus. J Neurol Sci 12: 77-93

22. Gregory TJ, Wallis CJ, Printz MP (1982) Regional changes in rat brain angiotensinogen following bilateral nephrectomy. Hypertension 4: 827-838

23. Rapaport SI (1976) Blood-brain barrier in physiology and medicine. Raven, New York, p 76-78

24. Kirber WM, Nichols CW, Grimes PA, Winegrad AI, Laties AM (1980) A permeability defect of the retinal pigment epithelium: occurrence in early streptozotocin diabetes. Arch Ophthalmol 98: $725-728$

25. Swanson LW, Kucharczyk J, Mogenson GJ (1978) Autoradiographic evidence for pathways from the medial preoptic area to the midbrain involved in the drinking response to angiotensin II. $\mathbf{J}$ Comp Neurol 178: 645-660

26. Smith QR, Johanson CE, Woodbury DM (1981) Uptake of ${ }^{36} \mathrm{Cl}$ and ${ }^{22} \mathrm{Na}$ by the brain-cerebrospinal fluid system: comparison of the permeability of the blood-brain and blood-cerebrospinal fluid barriers. J Neurochem 37: 117-124

27. Maccario M (1968) Neurological dysfunction associated with nonketotic hyperglycemia. Arch Neurol 19:525-534

28. Johansen K, Hansen AP (1971) Diurnal serum growth hormone levels in poorly and well-controlled juvenile diabetics. Diabetes 20: $239-245$

29. Hansen AP (1970) Abnormal serum growth hormone response to exercise in juvenile diabetics. J Clin Invest 49: 1467-1478

30. Guthrow CE, Morris MA, Day JF, Thorpe SR, Baynes JW (1979) Enhanced nonenzymatic glucosylation of human serum albumin in diabetes mellitus. Proc Natl Acad Sci USA 76: 4258-4261

31. Williams SK, Devenny JJ, Bitensky MW (1981) Micropinocytic ingestion of glycosylated albumin by isolated microvessels: possible role in pathogenesis of diabetic microangiopathy. Proc Natl Acad Sci USA 78: 2393-2397

Received: 2 February 1985

and in revised form: 28 October 1985

Dr. Mara Lorenzi

Department of Medicine H-811-C

U.C.S.D. Medical Center

225 Dickinson Street

San Diego, CA 92103

USA 